\title{
Dynamical Donwscaling for Railroad Areas in Eastern Amazon and Southeastern Brazil: Current Climate and Near-Future Projections
}

\author{
Everaldo B. De Souza, Bergson C. de Moraes, Douglas B. S. Ferreira, \\ Luiz Gylvan Meira Filho \\ Instituto Tecnológico VALE-ITV, Grupo de Pesquisa sobre Mudanças do Clima, Belém, Brazil \\ Email: everaldo.barreiros.souza@itv.org
}

Received 24 December 2013; revised 20 January 2014; accepted 28 January 2014

Copyright (C) 2014 by authors and Scientific Research Publishing Inc.

This work is licensed under the Creative Commons Attribution International License (CC BY). http://creativecommons.org/licenses/by/4.0/

\begin{abstract}
We performed a dynamic downscaling using REGCM4 regional model driven by MPI global model for current $(1990 / 2012)$ and near-future $(2015 / 2039)$ climate in order to characterize the seasonal rainfall regimes throughout the railroad areas in eastern Amazon and southeastern Brazil. The analysis of observational data for the current climate indicated the existence of pronounced spatial variations in rainfall regime across railroad regions during both the rainy and dry seasons. Although models have presented generalized underestimation, the regional model showed improvements on spatial representation and intensity of the rainfall in comparison with global model results. We reported the future projections taking into account the correction of simulated rainfall by the values of the biases found in each respective seasonal regime, so that the results are expressed by percentage changes of the future $(2015 / 2037)$ relative to the current climate patterns. For the railroad in eastern Amazon, projections indicate a weak decrease of rainfall of about $\mathbf{- 1 5 \%}$ in the rainy season (January to May), however during the dry season (June to October) are expected drastic reductions between $\mathbf{- 7 0 \%}$ and $\mathbf{- 9 0 \%}$ in south (Carajás in Pará state) and north (São Luis in Maranhão state) portions. Conversely, for the railroad in southeast Brazil, model projections point out for an increased rainfall regime during the rainy season (October to February) around $+30 \%$ to $+40 \%$ in the east part of the region over the Espírito Santo state.
\end{abstract}

\section{Keywords}

Regional Climate Modeling; Rainy and Dry Seasons; Climate Change; Brazil Climate; REGCM4 


\section{Introduction}

After the agriculture sector, the industry particularly in the mining sector is what has contributed significantly to the Brazilian economy in recent years, so that Brazil has occupied the second position in exports of iron ore globally [1]. VALE is the main Brazilian company that exports iron ore to many countries (leading importer is China). In this context, the Carajás railroad-EFC (located between the states of Pará and Maranhão in eastern Brazilian Amazon) and also the Vitória-Minas railroad-EFVM (located between the states of Minas Gerais and Espírito Santo in southeastern Brazil) are extremely important for the VALE's ore transporting operational activities.

From the point of view of weather and climate, such VALE operations may be impacted seasonally by different hydroclimatic conditions during the first and second half of the year, when are observed the maximum and minimum of the rainfall annual cycle in most regions of Brazil [2] [3]. In the first semester, the rainiest season of the year, there are episodes of intense rainfall of short duration (few hours), associated with severe weather systems, and long duration events (days to weeks) related to persistent climate patterns, which provoke generally the occurrence of floods in the rivers. On the other hand, in the second semester, driest period of the year, there are prolonged droughts (lack of rainfall) that commonly are associated with conditions of fires particularly in eastern Amazon. Such seasonal phenomena induce negative impacts on ore transport operations, since they can result in decreasing the speed of trains or even cause temporary outages, and are complicating factors in terms of the logistics required to perform the activities of both general operation and maintenance.

Nevertheless, in the context of discussions on global climate change, the IPCC-Intergovernmental Panel on Climate Change in its 5th report-AR5 [4] points out to significant changes in climate patterns across the Brazilian territory during next decades (mid to end of the century XXI). There is a consensus in the scientific community [5] that one of the most appropriate tools for generation of climate projections is the dynamic downscaling, whose technique consists in performing a regional model nested with a global model. Basically, the outputs of global model with lower spatial resolution $(\sim 200 \mathrm{~km})$ are used as boundary conditions within the regional model that performs simulations in a higher spatial resolution $(\sim 20-50 \mathrm{~km})$. Several studies suggest that the downscaling provides a more realistic representation of the climate where local factors (proximity to the ocean, steep topography, soil and heterogeneous surface coverage, etc.) that in principle are captured by the regional models, serve as important modulators of weather/climate conditions, added to the large-scale factors (modulation of the oceans and atmospheric general circulation) that are captured by the global models [6].

The focus of the present work is to conduct a dynamic downscaling using the version 4.3 of the Regional Climate Model (REGCM4) driven by Max Planck Institute (MPI) global model simulations used in IPCC AR5. Our objectives are: 1) to characterize seasonal rainfall patterns during the rainy and dry seasons in the EFC and EFVM regions, based on analysis of observational data and on global and regional climate simulations during the last 23 years (1990-2012), period considered as current climate; 2) to report some projections of changes in these seasonal rainfall regimes for the next 23 years (2014-2039), considered as near-future climate.

\section{Data, Methods and Climate Models}

Figure 1 illustrates the study area covering the regions of EFC and EFVM railroads. EFC extends from Carajás in southeast Pará to the Sao Luis in Maranhão coastal region in eastern Amazon. EFVM extends from the eastern Minas Gerais to the Espírito Santo coast, bordering the river Doce on regions with steep topography in southeastern Brazil.

The observational data consist of monthly precipitation available on 0.5 horizontal resolution grid over Brazil from January 1990 to December 2012. These data were generated through the observational data analysis system from the Climate Prediction Center (CPC, NOAA, USA) and is based entirely on data registered by the meteorological stations [7]. Further details on quality control and technique of objective analysis and interpolation used in the CPC precipitation data can be found in [7]. Some studies demonstrated the existence of high consistency and correlation between the CPC data and those derived from conventional and satellite data [7] [8].

We use the MPI simulations, a global coupled model performed by the Max Planck Institute for Meteorology [9] which is considered state of the art in numerical simulation of the global climate system. The MPI outputs were prepared for the Coupled Model Intercomparison Project phase 5-CMIP5 (http://cmip-pcmdi.llnl.gov/cmip5) to compose the IPCC AR5. In the present study MPI data refer to the future scenario RCP4.5 (Representative Concentration Pathways, [10]) which is considered intermediate scenario in terms of global radiative forcing of 


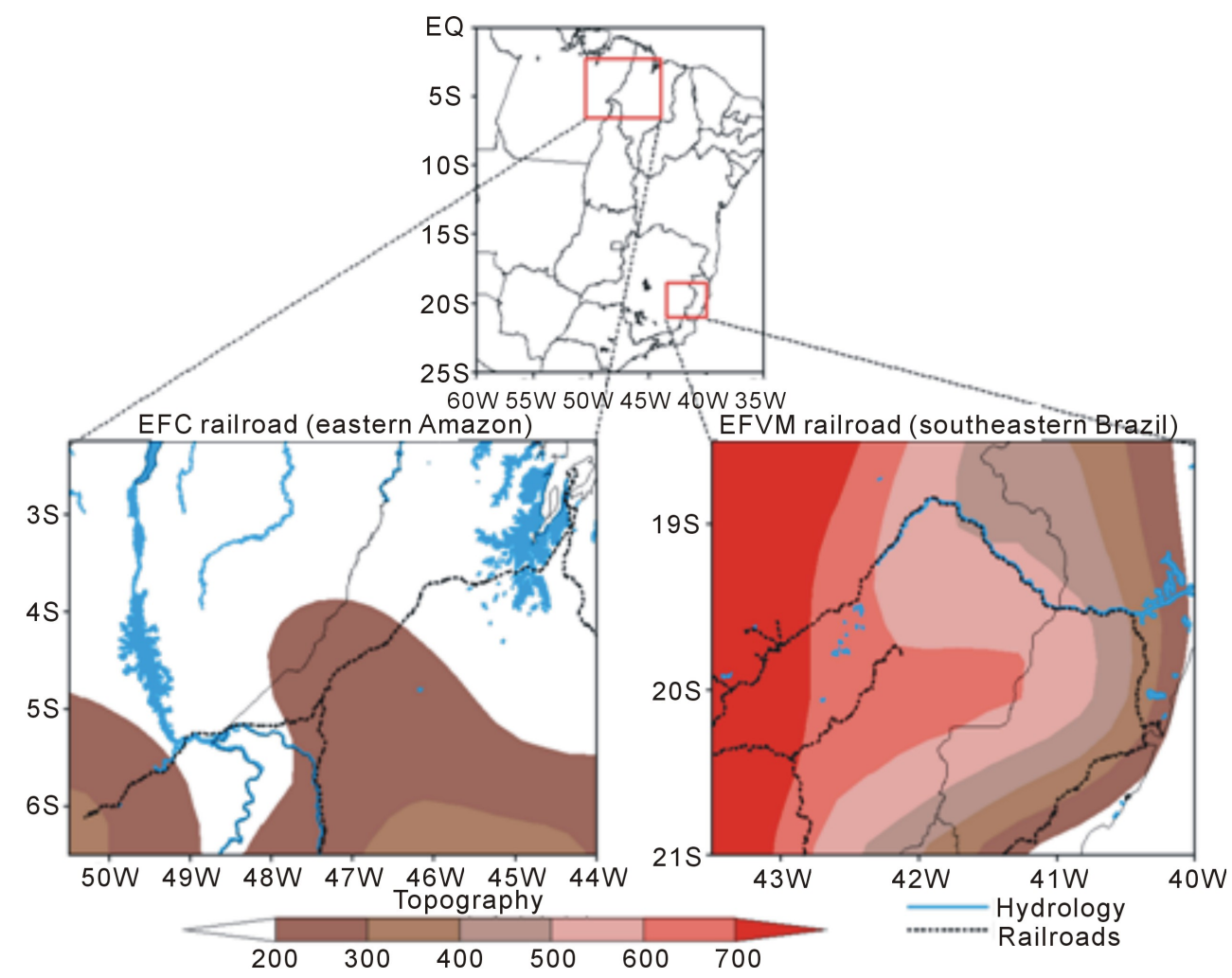

Figure 1. Study area over the regions of the EFC-Carajás railroad along the Pará and Maranhão states in eastern Amazon (left map) and EFVM-Vitória-Minas railroad along the Minas Gerais and Espírito Santo states in southeastern Brazil (right map). The dashed black line indicates the EFC and EFVM. Colors indicate topography in meters and blue lines show the main rivers.

approximately $4.5 \mathrm{~W} / \mathrm{m}^{2}$ ( 650 $\mathrm{ppm} \mathrm{CO}_{2}$ equivalent) by the year 2100 .

Also we used the version 4.3 of the Regional Climate Model-REGCM4, whose source code is kept under constant improvement and updating by the International Centre for Theoretical Physics-ITCP

(http://gforge.ictp.it/gf/project/regcm). The REGCM4 is the fourth generation of a regional climate model originally developed at NCAR [11] and later improved by ICTP [6]. REGCM4 is a community, limited area model in sigma-p vertical coordinate and Arakawa-B horizontal grid, with the primitive equations for compressible and hydrostatic fluid. Details on physical model, surface, radiative transfer and ocean fluxes schemes, and parameterization of convective and large scale precipitation are fully described in [12]. Here we use the REGCM4 configuration proposed by [13] and [14] that implemented changes in Grell convection scheme (time of convection trigger) and the BATS surface scheme (water content and soil hydraulic conductivity). Such modifications produced qualitatively and quantitatively better climate simulations than previous studies for the summer and winter patterns in southeastern Brazil [15] and for eastern Amazon rainy season [8] [16]. This regional model was installed on Vale Institute of Technology (ITV) using state-of-the-art in high-performance computer simulation using a Cluster with 196 processors. Regional simulations for this study were generated in an area centered in Amazon $\left(4^{\circ} \mathrm{S}-59^{\circ} \mathrm{W}\right)$ using the normal Mercator projection with 192/96/18 points in the zonal/meridional/vertical directions, grid spacing of $50 \mathrm{~km}$ and a step time of 30 minutes. The model was initialized with the 6/6 hours boundary conditions from the MPI model during period 1990-2037.

The analysis procedures used in this study are described below.

Definition of rainy and dry seasons: analyses were conducted for the seasonal periods (five consecutive months) when it is observed the highest (rainy season) and lowest (dry season) amount of rainfall throughout the year. For the EFC region the rainy season occurs from January to May, while the EFVM region is from October to February. The dry season in both the EFC and EFVM is coincident from June to October.

Climatological means: observational aspects of the seasonal rainfall regimes throughout the EFC and EFVM 
regions are based on the climatological average, i.e., the calculation of averages considering the time series from 1990 to 2012. This period comprises current climate conditions over the last 23 years.

Projections of future climate: Firstly, we assessed the ability of the global and regional models to reproduce the observed rainfall patterns by calculating the relative bias, considering the current climate conditions. After, we present the future climate projections generated by the MPI and REGCM4 models for both the rainy and dry seasons as changes, i.e., the percentage difference between the future climate (2015/2037) and current climate (1990/2012). If the result of this difference is a positive (negative) value, it means that the model indicates an increase (decrease) of precipitation in the future climate. Values near zero indicate neutrality or without significant changes. Nevertheless, it was decided to present the projections of changes taking into account the correction of the amount of simulated rainfall by the biases. For example, for a given location, a value of $10 \mathrm{~mm}$ for observed rainfall and $8 \mathrm{~mm}$ for simulated rainfall during current climate (1990/2012), we have bias $-2 \mathrm{~mm}$ or $-20 \%$. In the simulation of future climate for a value of $7 \mathrm{~mm}$, it follows that the difference [current climate - future climate simulations $]=-1 \mathrm{~mm}$, a decrease of $-10 \%$. However, considering that former bias of $-20 \%$, which we assume to be perpetuated in future simulations, then we have a corrected value of $5 \mathrm{~mm}$ for the simulated rainfall in the future climate, which represents a decrease $-5 \mathrm{~mm}$ or $-50 \%$. This criterion of correctness of the change in the sign of precipitation, considering the model systematic error, was included in the results of future climate projections.

\section{Results}

\subsection{The Current Climate (1990-2012)}

The climatological characteristics of the rainfall regimes during the rainy and dry seasons along the EFC and EFVM regions, considering the current climate (1990-2012), are showed in Figures 2 and 3, respectively. The analyses are emphasized for regions along these two railroads.

For the EFC region, during the rainy season (January to May), it is observed rainfall (Figure 2(a), top left map) more intense between 9 and $11 \mathrm{~mm}$ in the northern portion of the railroad in northeastern Maranhão (from Santa Inês to São Luis) and rainfall relatively more weak between 5 and $7 \mathrm{~mm}$ in the central and southern part of the EFC in the southeast of Pará (Carajás to Marabá) and southwest of Maranhão (Açailândia to Buriticupu). The simulated rainfall by the global climate model MPI (Figure 2(a), top middle map) shows values from 2 to 5 $\mathrm{mm}$ in the northern part and 5 to $8 \mathrm{~mm}$ in the central and southern part of the EFC. The results of the regional model REGCM4 (Figure 2(a), top right map) show improvements in simulations of precipitation in the northern part with increased values to 6 - $8 \mathrm{~mm}$. On the other hand, during the dry regime (June to October), the observed rainfall presents minimum values between 0.5 and $1 \mathrm{~mm}$ in the central (near Açailândia) Maranhão, while the portions of the north (Vitória do Mearim to São Luis) and south (Carajás to Maraba ) have relatively higher values ranging between 1 and $2 \mathrm{~mm}$ (Figure 2(b), bottom left map). MPI model indicates generalized values of 0.5 $\mathrm{mm}$ across entirely railroad (Figure 2(b), bottom middle map) and REGCM4 model simulated a better rainfall regime with values between 1 and $1.5 \mathrm{~mm}$ along the EFC (Figure 2(b), bottom right map).

For the EFVM region, during the rainy regime (October to February) the observations show rainfall with highest intensity, 5 to $7 \mathrm{~mm}$, in the west part of railroad in Minas Gerais (between Itabira and Ipatinga ), while the east portion since Aimorés in Minas Gerais up to Vitória in Espírito Santo presents lower rainfall between 4 and $5 \mathrm{~mm}$ (Figure 3(a), top left map). The precipitation simulated by the MPI (Figure 3(a), top middle map) shows values between 5 and $6 \mathrm{~mm}$ throughout the region and the REGCM4 (Figure 3(a), top right map) simulated values between 6 and $7 \mathrm{~mm}$ in the western portion compatible with the observed data, but in the eastern portion in the Espírito Santo the values between 6 to $7 \mathrm{~mm}$ indicate that the regional model overestimated the observed data. On the other hand, the spatial distribution of rainfall observed during the dry season (June to October) shows smaller values, 1 to $1.5 \mathrm{~mm}$, in most of Minas Gerais, while in the Espírito Santo the rainfall is relatively higher between 2 and $3 \mathrm{~mm}$ (Figure 3(b), bottom left map). The simulated rainfall by MPI model (Figure 3(b), bottom middle map) exhibits values between 1 and $1.5 \mathrm{~mm}$ across the region, while REGCM4 model (Figure 3(b), bottom right map) simulate very well the spatial pattern with smaller volumes over Minas Gerais (between 1 and $1.5 \mathrm{~mm}$ ) and higher volume in the Espírito Santo (between 1.5 and $2 \mathrm{~mm}$ ).

\subsection{Projections of Near-Future Climate (2015-2039)}

The changes in the rainfall regime as projected by the MPI and REGCM4 for the next 23 years (2015/2037) are 
(a) EFC-rainy season (January to May)
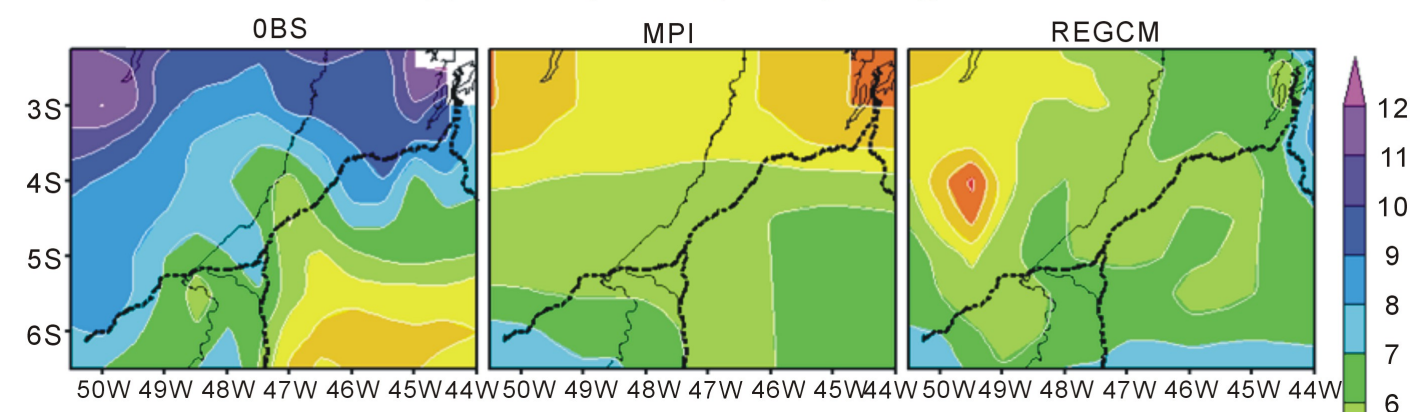

(b) EFC-dry season (June to October)
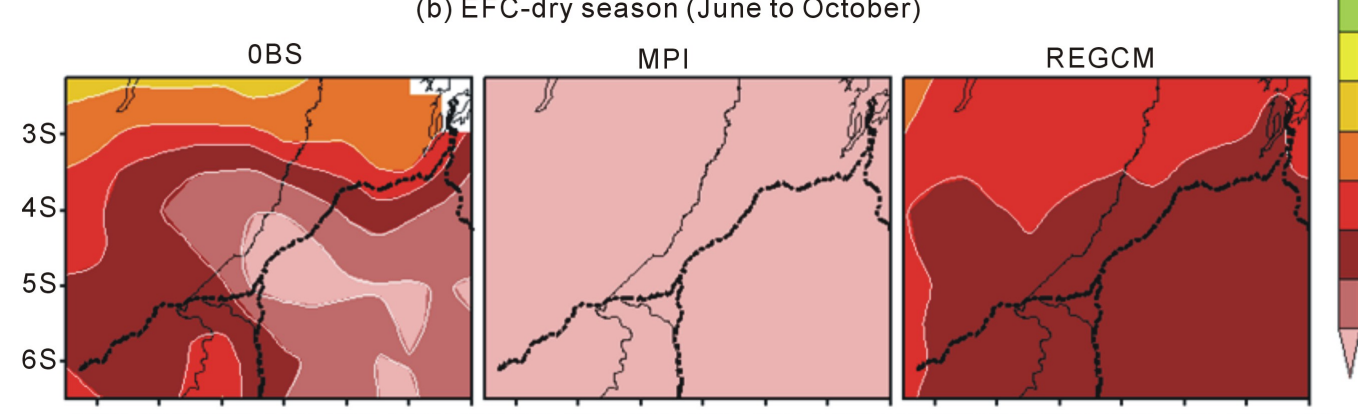

50W 49W 48W 47W 46W 45W44W50W 49W 48W 47W 46W 45W44W 50W49W 48W 47W 46W 45W 44W

Figure 2. Spatial distribution of seasonal rainfall (23-yr average: 1990/2012 ) during the (a) January to May rainy season and (b) June to October dry season considering the OBS—observed data (left), and simulations with MPI global model (middle) and REGCM4 regional model (right). The dashed line indicates the EFC railroad between the states of Pará and Maranhão. The intensity of rainfall $(\mathrm{mm})$ is indicated in the color scale.

(a) EFVM-rainy season (October to February)

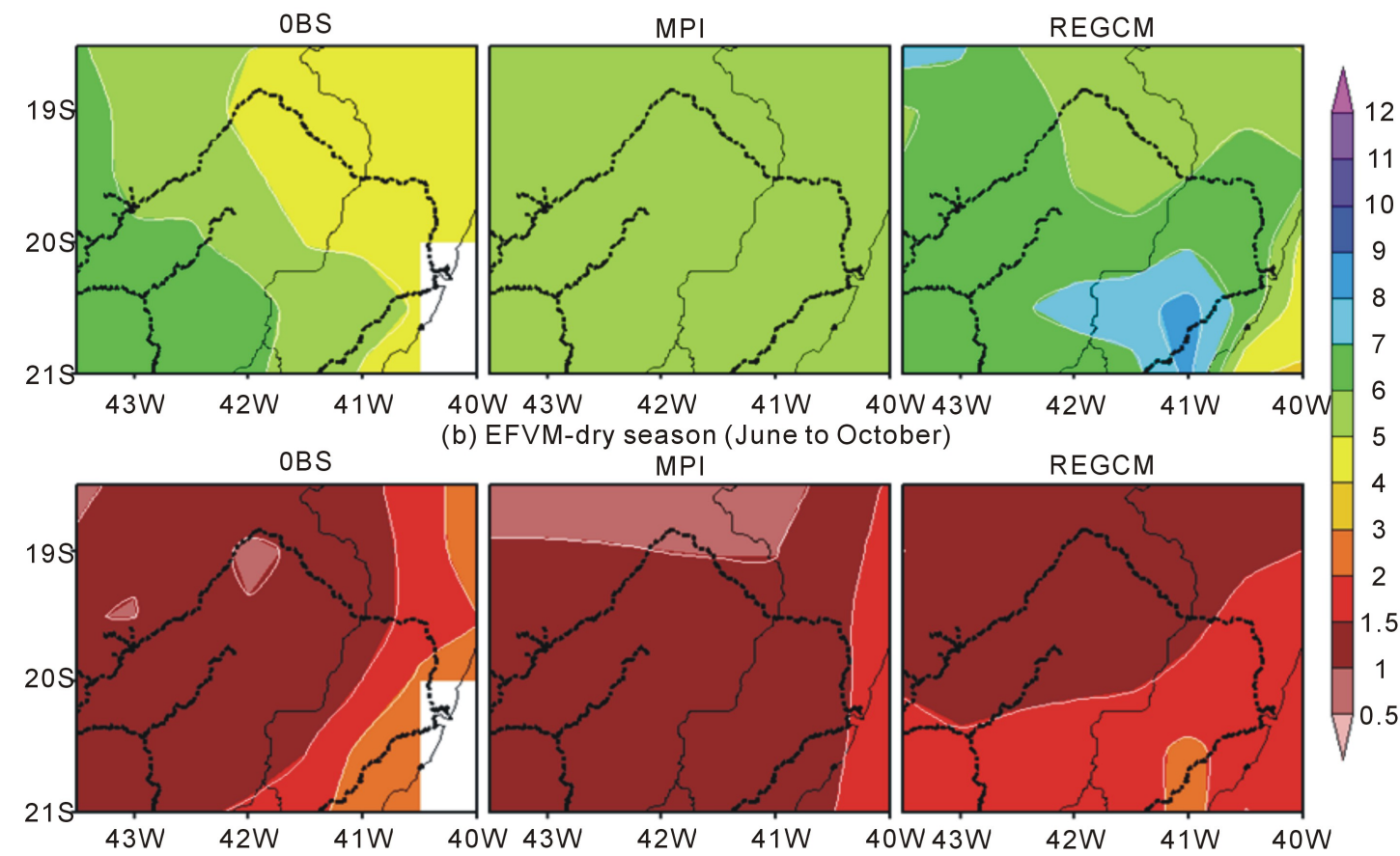

Figure 3. Spatial distribution of seasonal rainfall (23-yr average: 1990/2012) during the (a) October to February rainy season and (b) June to October dry season considering the OBS - observed data (left), and simulations with MPI global model (middle) and REGCM4 regional model (right). The dashed line indicates the EFVM railroad between the states of Minas Gerais and Espírito Santo. The intensity of rainfall (mm) is indicated in the color scale. 
presented below. Such simulations of future climate are analyzed taking into account the errors (magnitude and sign of the biases) of each model, in order to correct the amount of simulated rainfall (see procedure described in Section 2) by the observations and thus the projections are percentage values relative to the 1990/2012 climate conditions. Again we mention that the results are emphasized for neighboring regions along the railroads.

For the rainy season of the EFC region in eastern Amazon, the MPI global model indicates no signal changes in the south portion (Carajás), increase of $+10 \%$ to $+30 \%$ in the central part, and high decrease of rainfall between $-10 \%$ to $-50 \%$ in north section (Vitória do Mearim to Sâo Luis) in Maranhão state (Figure 4(a), top left map). Results obtained from REGCM4 regional model (Figure 4(a), top right map) are partially in agreement with MPI in showing small areas with positive and negative values ranging $10 \%$ to $30 \%$ in central regions of railroad, however particularly for the north sector (São Luis in the Maranhão coast) REGCM4 points out no changes. On the other hand, for the dry season of the EFC region, both the MPI and REGCM4 models indicate the predominance of decreased precipitation along the railroad. MPI shows significant decrease of $-90 \%$ in the extreme south and north portions and $-70 \%$ to $-90 \%$ in central sector of the EFC (Figure 4(b), bottom left map). REGCM4 suggests relatively lower values with $-50 \%$ to $-70 \%$ in south and north sectors, and $-10 \%$ to $-30 \%$ in the central sector of the EFC (Figure 4(b), bottom right map).

In the future climate projections for the rainy season of the EFVM in southeastern Brazil, both the models exhibits increase of rainfall along most of railroad with values projected by the MPI (Figure 5(a), top left map) oscillating between $+10 \%$ to $+50 \%$ and values simulated by the REGCM4 (Figure 5(a), top right map) much more intense ranging $+50 \%$ to $+90 \%$. On the other hand, the results obtained for the rainfall regime during the dry season are inverses, so that MPI (Figure 5(b), bottom left map) shows reduced rainfall of about $-10 \%$ to $-30 \%$ in central to east portions, while REGCM4 (Figure 5(b), bottom left map) presents intensified rain of $+10 \%$ to $+30 \%$ in the central to west part of the EFVM.

\section{Discussion and Concluding Remarks}

We performed a dynamic downscaling using REGCM4 regional model driven by MPI global model for current (1990 to 2012) and near-future (2015 to 2039) climate conditions in order to characterize the seasonal rainfall regimes throughout railroad regions in the EFC (Pará/Maranhão states) in eastern Amazon and EFVM (Minas Gerais/Espírito Santo states) in southeastern Brazil.

(a) EFC-Rainy season

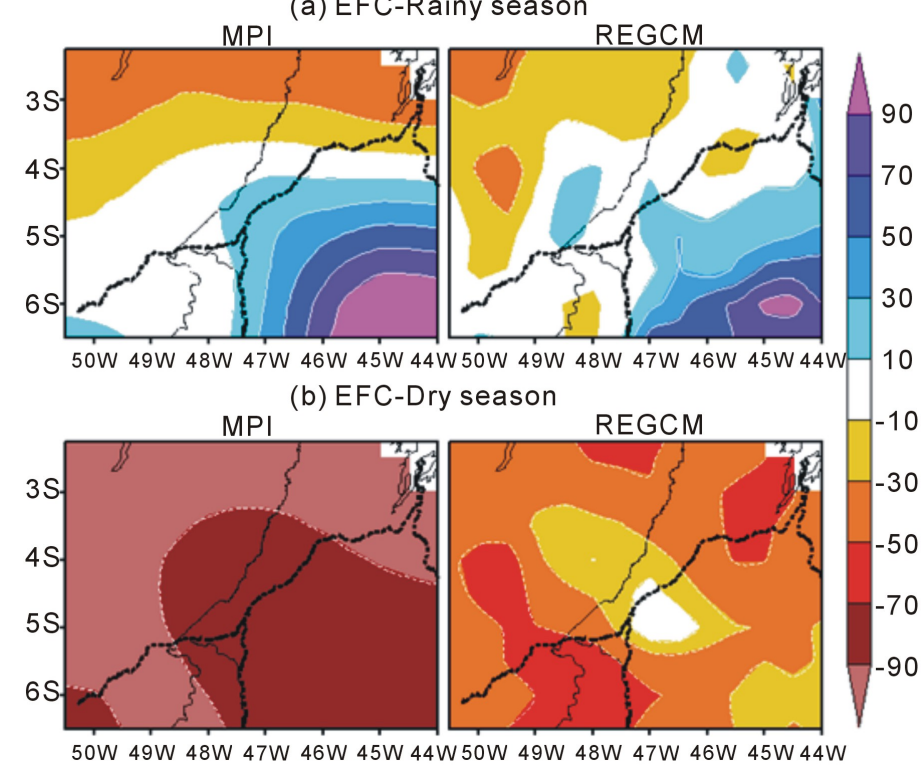

Figure 4. Percentage changes in precipitation for the (a) rainy (b) dry season by the MPI global model (left) and REGCM4 regional model (right) for the next 23 years (2015/2037). The dashed line indicates the EFC railroad between the states of Pará and Maranhão. The intensity of changes (unit: \%) is indicated in the color scale. 
(a) EFVM-Rainy season

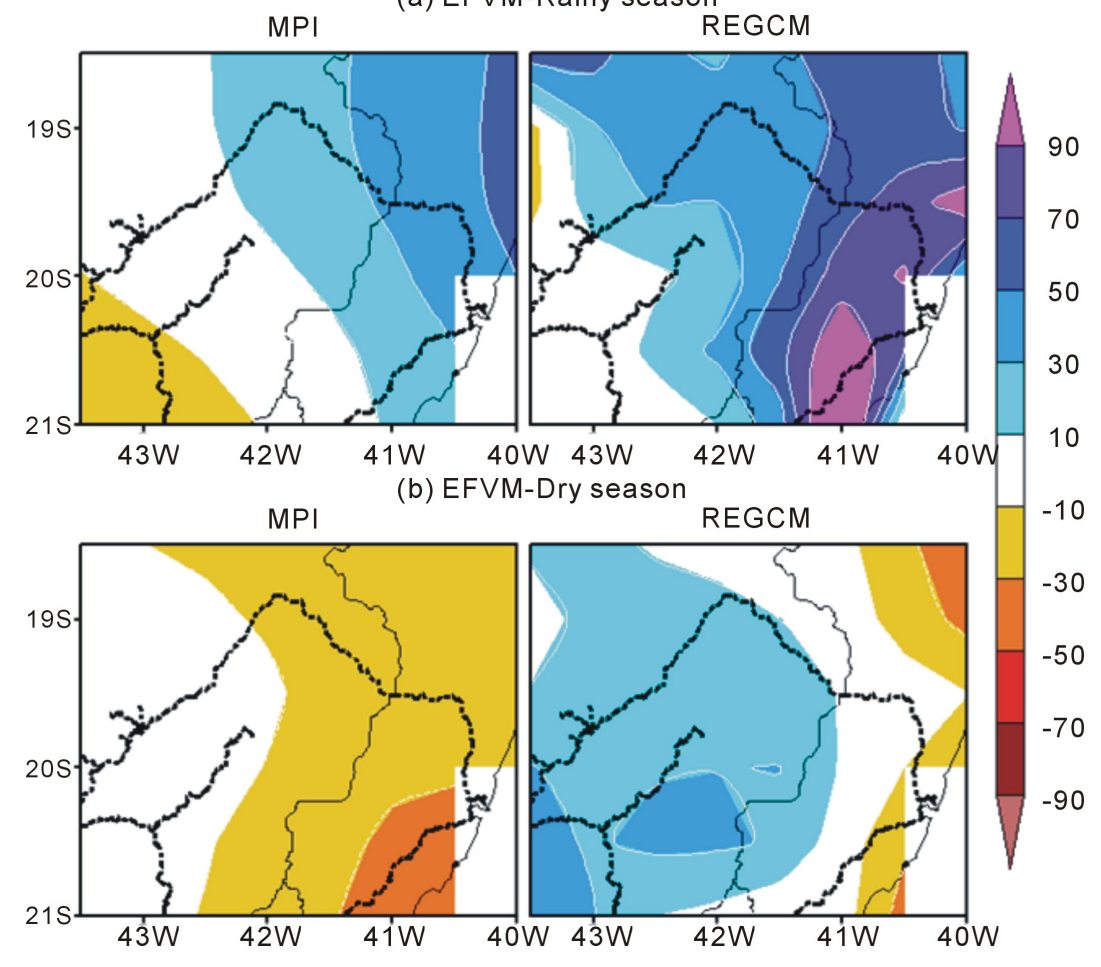

Figure 5. Percentage changes in precipitation for the (a) rainy (b) dry season by the MPI global model (left) and REGCM4 regional model (right) for the next 23 years (2015/2037). The dashed line indicates the EFVM railroad between the states of Minas Gerais and Espírito Santo. The intensity of changes (unit: \%) is indicated in the color scale.

The analysis of observational data for the current climate indicated the existence of pronounced spatial variations in rainfall regime across regions of the EFC and EFV during both the rainy and dry seasons. These results are consistent with observational analysis that used stations and satellite data [3] [7] [8] [17]. Although models have presented generalized underestimation, the REGCM4 regional simulations for the current climate rainfall patterns showed improvements on spatial representation and intensity of the rainfall in comparison with the MPI global model results.

We reported the projections of future climate taking into account the correction of simulated rainfall by the values of the biases found in each respective seasonal rainfall regimes. Thus we avoid partially the problem of uncertainty in models concerning the systematic errors, so that the results are expressed by percentage changes of the near-future (2015/2037) relative to the present (1990/2012) climate patterns.

For the region of the EFC railroad in eastern Amazon, the projections indicate a weak decrease of around -15\% of the rainfall in the rainy season (January to May), however during the dry season (June to October ) are expected drastic reductions between $-70 \%$ and $-90 \%$ in south (Carajás in Pará state) and north (São Luis in Maranhão state) sectors. These drier conditions may probably aggravate the events of fire associated with prolonged periods of drought with low humidity and high air temperature during the second semester of the year. Conversely, for the region of EFVM railroad in southeast Brazil, model projections point out for an increased rainfall regime during the rainy season (October to February) around $+30 \%$ to $+40 \%$ in the east part of the region over the Espírito Santo state. These changes can probably result in amplification of the floods with landslides in mountainous areas due prolonged periods of rainfall. These findings are consistent with long-term climate projections for the different Brazilian regions reported by [5] [18].

The results here presented are promising in indicating that regional climate modeling is a powerful tool for improving the scientific knowledge on tropical climate and also to expand our capacity to generate products applied to the specific interests of the productive sectors. These climate informations are relevant for VALE in is- 
sue of long-term planning particularly in operating activities along the EFC and EFVM railroads regions.

\section{Acknowledgements}

The authors thank ICTP team for providing REGCM4 code. E. B. De Souza is partially sponsored by CNPQ (PQ2 Proc. 3073980/2010-6 and Universal project Proc. 484779/2012-5).

\section{References}

[1] Lopes, M.M., Silva, R.A. and Coronel, D.A. (2013) Competitiveness of Brazilian Exports of Iron Ore (1999-2012). Proceedings 2nd International Forum ECOINOVAR (ECO INNOVATION International Forum), Santa Maria, 23-24 September 2013, 1-8.

[2] De Souza, E.B. and Ambrizzi, T. (2004) Pentad Precipitation Climatology over Brazil and the Associated Atmospheric Mechanisms. Climanálise, 1, 1-25.

[3] Reboita, M.S., Gan, M.A., da Rocha, R.P. and Ambrizzi, T. (2010) Regimes de precipitação na América do Sul: Uma revisão bibliográfica. Revista Brasileira de Meteorologia, 25, 185-204. http://dx.doi.org/10.1590/S0102-77862010000200004

[4] (2013) IPCC AR5: Summary for Policymakers. In: Stocker, T.F., Qin, D., Plattner, G.-K., Tignor, M., Allen, S.K., Boschung, J., Nauels, A., Xia, Y., Bex, V. and Midgley, P.M., Eds., Climate Change 2013: The Physical Science Basis, Contribution of Working Group I to the Fifth Assessment Report of the Intergovernmental Panel on Climate Change, Vol. 1,Cambridge University Press, Cambridge and New York, 33 p.

[5] PBMC—Painel Brasileiro de Mudanças Climáticas (2013) Sumário Executivo-Base Científica das Mudanças Climáticas. Contribuição do Grupo de Trabalho 1 ao Primeiro Relatório de Avaliação Nacional do Painel Brasileiro de Mudanças Climáticas. Vol. 1, PBMC, Rio de Janeiro, 24 p.

[6] Pal, J.S., Giorgi, F., Bi, X., Elguindi, N., Solmon, F., et al. (2007) The ICTP RegCM3 and RegCNET: Regional Climate Modeling for the Developing World. Bulletin of the American Meteorolological Society, 88, 1395-1409. http://dx.doi.org/10.1175/BAMS-88-9-1395

[7] Silva, V.B., Kousky, S., Shi, V.W. and Higgins, R.W. (2007) An Improved Gridded Historical Daily Precipitation Analysis for Brazil. Journal of Hydrometeorology, 8, 847-861. http://dx.doi.org/10.1175/JHM598.1

[8] De Souza, E.B., Lopes, M.N.G., da Rocha, E.J.P., Souza, J.R.S., Cunha, A.C., et al. (2009) Precipitação climatológica sobre a Amazônia oriental durante o período chuvoso: Observações e simulações regionais com o RegCM3. Revista Brasileira de Meteorologia, 24, 111-124. http://dx.doi.org/10.1590/S0102-77862009000200001

[9] Raddatz, T., Reick, C., Knorr, W., Kattge, J., Roeckner, E., et al. (2007) Will the Tropical Land Biosphere Dominate the Climate-Carbon Cycle Feedback during the Twenty-First Century? Climate Dynamics, 29, 565-574. http://dx.doi.org/10.1007/s00382-007-0247-8

[10] van Vuuren, D.P., Edmonds, J., Kainuma, M., Riahi, K., Thomson, A., et al. (2011) The Representative Concentration Pathways: An Overview. Climatic Change, 109, 5-31. http://dx.doi.org/10.1007/s10584-011-0148-z

[11] Giorgi, F. and Bates, G.T. (1989) The Climatological Skill of a Regional Climate Model over Complex Terrain. Monthly Weather Review, 117, 2325-2347. http://dx.doi.org/10.1175/1520-0493(1989)117<2325:TCSOAR>2.0.CO;2

[12] Giorgi, F., Copola, E., Solmon, F., Mariotti, L., Sylla, M.B., et al. (2012) RegCM4: Model Description and Preliminary Tests over Multiple CORDEX Domains. Climate Research, 52, 7-29. http://dx.doi.org/10.3354/cr01018

[13] Da Rocha, R.P., Morales, C.A., Cuadra, S.V. and Ambrizzi, T. (2009) Precipitation Diurnal Cycle and Summer Climatology Assessment over South America: An Evaluation of Regional Climate Model Version 3 Simulations. Journal of Geophysical Research, 114, Article ID: D10108. http://dx.doi.org/10.1029/2008JD010212

[14] Da Rocha, R.P., Cuadra, S.V., Reboita, M.S., Kruger, L.F., Ambrizzi, T. and Krusche, N. (2012) Effects of RegCM3 Parameterizations on Simulated Rainy Season over South America. Climate Research, 52, 253-265. http://dx.doi.org/10.3354/cr01065

[15] Cuadra, S.V. and da Rocha, R.P. (2006) Simulação numérica do clima de verão sobre o Brasil e sua variabilidade. Revista Brasileira de Meteorologia, 21, 271-282.

[16] Machado, R.D. and Da Rocha, R.P. (2011) Previsões climáticas Sazonais sobre o Brasil: Avaliação do RegCM3 aninhado no modelo global CPTEC/COLA. Revista Brasileira de Meteorologia, 26, 121-126.

[17] Moraes, B.C., Ferreira, D.B.S., Meira Filho, L.G., Oliveira, J.V., De Souza, E.B., et al. (2013) Comparative Skill of Numerical Weather Forecasts in Eastern Amazonia. Atmospheric and Climate Sciences, 3, 355-363. http://dx.doi.org/10.4236/acs.2013.33037

[18] Marengo, J.A., Chou, S.C., Kay, G., Alves, L.M., Pesquero, J.F., et al. (2012) Development of Regional Future Cli- 
mate Change Scenarios in South America Using the Eta CPTEC/HadCM3 Climate Change Projections: Climatology and Regional Analyses for the Amazon, São Francisco and the Paraná River Basins. Climate Dynamics, 38, 18291848. http://dx.doi.org/10.1007/s00382-011-1155-5 